\title{
The genetics of complex ophthalmic disorders
}

\author{
K Evans, AC Bird
}

'Complex inheritance' is a relatively new term for multifactorial, polygenic, or quantitative inheritance that identifies characteristics, traits, or diseases that are determined by a number of genes. In some cases there may also be an environmental component to aetiology. Examples of such disorders are Alzheimer's disease, schizophrenia, bipolar affective disorder, hypertension, heart disease, and arthritis. In the 19th century this phenomenon was recognised as 'blending of inheritance' with progeny exhibiting phenotypes intermediate between parents. One of the great achievements of mendelian genetic (particulate) theory leading to its general acceptance was to explain this effect as the transmission of many different mendelian factors. ${ }^{1}$

In developed countries the three most prevalent causes of blindness-age-related macular degeneration (ARMD), diabetic retinopathy, and glaucoma ${ }^{2}$ are all thought to be aetiologically complex. Progress in molecular genetics now gives us sufficient understanding of the structure of the genome and the refined techniques to be able to begin to unravel their complexity with the promise of developing novel approaches to the management of patients with these conditions.

In this article an overview of the published work on aetiological influences in each of these diseases is presented with an outline of the molecular genetic methods that are most likely to lead to the identification of the responsible genetic abnormalities.

\section{Age-related macular degeneration}

In Great Britain, 50\% of the 35000 blind and partially sighted registrations per year are attributable to ARMD and recent reports suggest that the incidence of the disease is rising. ${ }^{3}$ The term ARMD applies to patients over 50 years of age and describes morphological changes at the macula which include soft drusen, abnormal pigmentation, geographic atrophy, and subretinal neovascularisation with subretinal scarring. ${ }^{4}$ Importantly, these features can be signs of other retinal dystrophies (for example, Sorsby's fundus dystrophy, Doyne's honeycomb dystrophy, malattia levantinese) which can usually be differentiated from ARMD on the basis of establishing the appearance of these signs in other members of the patient's family before the sixth decade of life. ${ }^{5}$ It should be stressed that this definition does not assume that ARMD is a single aetiological entity.

\section{GENETIC INFLUENCES}

Many studies have suggested a role for genetics in the aetiology of ARMD and it seems likely that genetic predisposition is the strongest risk factor apart from advanced age. Hyman et $a l^{6}$ in a case-control study identified a significant increase in the incidence of ARMD in the siblings of affected individuals. This family association has been confirmed in twin studies ${ }^{7-9}$ and Silvestri et $a l^{10}$ have suggested a 19 times relative risk of the condition in family members of affected individuals. Piguet et $a l^{11}$ compared sibling pairs with spouses and demonstrated concordance of macular drusen between siblings but not with spouses sharing a common environment. This suggested that genetic background was the most important aetiological factor.

Further evidence suggesting a role for genetic influences has been the possible associations between $\operatorname{sex}^{12}$ and race $^{13}$ and ARMD. This latter association may involve the protective effect of ocular pigmentation as reflected in iris colour ${ }^{14}$ or changes in iris colour with age. ${ }^{15}$ Heiba et $a l^{16}$ undertook sibling correlation studies to quantify the role of genetic influences in ARMD in 564 families. A major genetic influence was confirmed in the aetiology of ARMD. Moreover, it was concluded, a single major gene could account for most of the variability of disease in this community. No specific gene or genomic locus has yet been positively associated with ARMD. The various genetic loci linked to monogenetic disorders that affect the macula, ${ }^{18}{ }^{18}$ in particular those loci that include the retinal genes peripherin $/ R D S^{19}$ and TIMP ${ }^{20}$ would be appropriate starting points for a genome search for ARMD susceptibility genes.

ENVIRONMENTAL INFLUENCES

Weaker and inconsistent risks have been found with a wide range of other exposures. For example, cardiovascular disease, ${ }^{2122}$ alcohol consumption (specifically beer), ${ }^{23}$ reproductive history, and exposure to exogenous oestrogens in women, ${ }^{24}$ smoking (most significantly associated with submacular neovascularisation), ${ }^{25}$ and plasticisers contaminating ingested food ${ }^{26}$ have all been associated with ARMD. This has led to the hypothesis that modification of environmental influences may lead to reduction of ARMD severity.

A major area of interest has been the influence of oxidative metabolism within the retina, light exposure, and the supplementation of diet with antioxidants. ${ }^{27}$ Normal metabolism with ultraviolet and high energy visible light exposure can trigger the formation of highly reactive free radicals leading to degradation of cellular proteins and polyunsaturated fatty acids. Cellular mechanisms designed to combat this may be particularly deficient in ARMD patients leading to accumulation of peroxidation products. Although histological changes similar to ARMD have been seen in animals exposed to light, no similar changes have been seen in human studies. Correlation of ARMD with antioxidant dietary content in humans has suggested possible protective roles for vitamins $A, C$, and $E$ and selenium. ${ }^{28}{ }^{29}$ Despite these positive associations between ARMD and environment, an almost equal number of studies find no associations. ${ }^{411}$

\section{Diabetic retinopathy}

Chronic hyperglycaemia is considered by far the major determinant of diabetic retinopathy. Previous controversy regarding the benefit of 'tight' control of hyperglycaemia 
has now been resolved with long term, strict control regimes resulting in significantly less progression of retinopathy. ${ }^{30} 31$ Other factors determining whether a patient with diabetes mellitus will develop retinopathy and its rate of progression probably exist. Prolonged hyperglycaemia secondary to other conditions-for example, pancreatitis, haemochromatosis, and acromegaly, are infrequently associated with retinopathy. ${ }^{32}$ The retinopathy seen in diabetes mellitus caused by mitochondrial mutations is atrophic rather than a vasculopathy. ${ }^{33}{ }^{34}$ Proliferative disease is more prevalent for any given duration of time in insulin dependent compared with non-insulin dependent cases. $^{35}{ }^{36}$ In addition, proliferative retinopathy is seen significantly more often in diabetics with HLA-DR phenotypes $4 / 0,3 / 0$, and $\mathrm{X} / \mathrm{X}$ when compared with control diabetic patients matched for age, sex, and duration of diabetes. ${ }^{37}$ The role of other components in the aetiology of diabetic retinopathy may be small. This is in contrast with diabetic nephropathy in which a significant, second component (genetic) in addition to hyperglycaemia has been proposed based on the observation that the incidence of nephropathy in insulin dependent diabetes, rather than steadily increasing with the duration of hyperglycaemia, declines rapidly after a period of 15 years. ${ }^{38}$ The underlying genetic abnormalities predisposing to systemic diabetes mellitus are therefore the most important factors in diabetic retinopathy aetiology. Whether one or more of the specific genetic abnormalities associated with systemic diabetes mellitus will be associated with an enhanced risk of retinopathy remains to be determined.

\section{GENETIC INFLUENCES}

Most work that has been undertaken on the aetiology of diabetes has related to type 1 or insulin dependent diabetes (IDDM). The importance of a genetic component has been established in many studies. The risk of IDDM in siblings of affected patients is on average $6 \%$ compared with a population frequency of only $0.4 \%$ in whites of European descent. ${ }^{39}$ Non-parametric linkage analysis in humans has identified at least 12 genetic loci contributing to the aetiology of IDDM.40 By far the most important (IDDM1) has been localised to the HLA region of chromosome $6 \mathrm{p} 21$ and relates to polymorphisms within the peptide binding sites of the class II molecules HLA-DQ and HLA-DR. IDDM1 accounts for $35 \%$ of the clustering observed in families. The next most significant association is with IDDM2 which localises to a variable number tandem repeat sequence in the insulin gene (INS) on chromosome $11 \mathrm{p} 15 .{ }^{40}$ Variation within the class I ( $\sim 40$ repeats) and class III ( $\sim 150$ repeats) alleles at this locus is thought to influence INS transcription, ${ }^{41}$ but a direct causal link between this effect and diabetes susceptibility has yet to be established. Other quantitatively less important loci are localised to chromosomes 15q, 11q13, $6 \mathrm{q} 25,18 \mathrm{q}, 2 \mathrm{q} 31,6 \mathrm{q} 27,3 \mathrm{q} 21-\mathrm{q} 25,10$ cen (IDDM3-10), the $\mathrm{X}$ chromosome (at locus $D X S 1068$ ), and the glucokinase gene $(G C K)$ on chromosome $7 \mathrm{p}^{40}$

Family and twin studies have also confirmed a strong genetic component to type 2 non-insulin dependent diabetes (NIDDM) ${ }^{42}$ although contrary to previous work this is not as great as is seen in IDDM. ${ }^{43}$ Again, mathematical modelling has pointed to the interaction of a number of genes. ${ }^{44}$ Maturity onset disease of the young (MODY) represents $2 \%$ of NIDDM cases. It is transmitted in a simple autosomal dominant fashion with mutations in the glucokinase gene $(G C K)$ and a locus on chromosome 20 accounting for $50 \%$ of cases and another locus on chromosome 12 accounting for a further $25 \%{ }^{45}$ Missense mutations of the glucagon receptor gene $(G C G-R)$ on chromosome $17 \mathrm{q} 25$ have been associated with a significant number of French NIDDM cases $^{46}$ and two studies on the genetic basis of NIDDM in the GK rat have highlighted susceptibility loci on rat chromosomes $1,2,5,10$, and $17 .^{47} 48$ The region linked to rat chromosome 1 is syntenic with human chromosome 11q15 where two genes, SUR and $B I R$, encoding constituents of pancreatic cell $\mathrm{K}+$ channels (KAPT) ${ }^{49}$ are found. Further work will determine whether the localisations identified in the GK rat will correspond to NIDDM loci in humans.

\section{ENVIRONMENTAL INFLUENCES}

Less emphasis has been placed on environment modulating diabetes susceptibility, although such influences are expected. The fact that only $10 \%$ of individuals with IDDM have a family history of the disorder, that epidemics of childhood diabetes have been reported, ${ }^{50}$ and that spatial clustering of IDDM occurs ${ }^{51}$ all suggest that genetic predisposition is only part of the story.

Stronger evidence for the role of environment has been obtained from concordance rates in monozygotic twins. Olmos et $a l^{52}$ have looked at the occurrence of IDDM in identical twins over a 24 year period. In this study of 49 IDDM patients, only 15 of their identical twins developed IDDM (30\%). Actuarial analysis further suggested that $94 \%$ of these identical twins who will develop IDDM will have done so within 30 years of its development in their sibling. The authors suggest that this implies genetic predisposition, with brief environmental exposure to a precipitating agent earlier in life. Infective agents seem the most likely. ${ }^{53}$ Observations on diabetic (NOD) mice suggested that the situation is more complicated. Those reared in germ free environments are more likely to develop the disease and viral infection in fact seems to reduce disease frequency. ${ }^{54}$ Advancing age, lack of physical activity, and obesity all contribute, along with genetic factors, in the aetiology of NIDDM. The specific risk of retinopathy in diabetes is also thought to be influenced by the presence of glaucoma, myopia and carotid occlusive disease (all thought to be protective), onset of puberty, pregnancy, and hypertension (all thought to adversely influence development and progression of retinopathy) ${ }^{55}$

\section{Genetic influences in glaucoma}

Glaucoma is the consequence of many clinically distinguishable entities. The commoner primary glaucomas will be discussed here rather than the secondary conditions where glaucoma is associated with, or is an outcome of, other ocular abnormalities. Primary glaucoma may be subdivided by age of onset into congenital (onset $<3$ years of age), juvenile (adolescent onset), and maturity onset disease (POAG). A genetic influence has been established for each subtype and these subdivisions to some extent seem to correspond to different genetic entities. Mainly recessive $^{56}$ but also dominant ${ }^{57}$ congenital glaucoma pedigrees have been reported. Dominant inheritance is found in juvenile disease ${ }^{58}{ }^{59} \mathrm{~A}$ history of simple mendelian inheritance is less often seen in POAG, ${ }^{60}{ }^{61}$ although $13-47 \%$ of POAG patients have a positive family history ${ }^{62}$ and there is a seven to tenfold increase in prevalence of POAG in the first degree relatives of POAG patients. ${ }^{6364}$ Twin studies have also shown a high concordance of POAG between monozygotic twins. ${ }^{65}$ Few studies have identified significant environmental risk factors for glaucoma although isotonic exercise and limiting alcohol and tobacco consumption can help to reduce intraocular pressure, if only transiently. ${ }^{66}$

A number of candidate regions (for example, $6 \mathrm{p} 21$, $6 p 25,11 p$, and 11q) have been proposed for congenital glaucoma based on chromosomal abnormalities identified cytogenetically where the condition was associated with 
multisystem abnormalities. Sarfarazi et al ${ }^{67}$ have shown tight linkage between autosomal recessive, simple, congenital glaucoma, and chromosome $2 \mathrm{p} 21$ in 11 of 17 Turkish families. This establishes the locus as important in the disease and suggests that recessive congenital glaucoma is genetically heterogeneous. However, confirmation of the quantitative significance of this result awaits studies in other ethnic groups. Linkage of autosomal dominant, juvenile glaucoma to chromosome 1q23-25 has been reported from a number of centres around the world. ${ }^{68}{ }^{69}$ Morissette et $a l^{70}$ have reported on a large French-Canadian pedigree, in which the disease was also linked to this chromosome 1q region. Interestingly, some family members with the disease haplotype had later onset glaucoma after 40 years of age. This implies that the disease gene mapping to this region may play a role in some cases of POAG. No other accounts of genetic abnormalities have been reported in other POAG groups although non-parametric linkage studies are under way. ${ }^{71}$ The possible roles of genes implicated in secondary glaucomas ${ }^{72}$ have not yet been fully assessed in POAG cases.

\section{Molecular genetic methodology}

Recombinant DNA technology and knowledge of the organisation of the human genome have become sufficiently refined over the past decade to make the task of identifying the genetic abnormalities leading to complex traits a practical possibility. Of particular importance has been the development of genetic markers (mapping to known genomic loci), based on the wealth of DNA polymorphisms that have been identified in the genome. These allow for the localisation of genetic abnormalities of interest to genomic regions sufficiently small to be screened using physical mapping technology. ${ }^{73}$ The task of identifying predisposing genetic abnormalities in complex traits proceeds along the following sequence of events: non-parametric linkage analysis to identify important genomic regions, locus refinement-for example, using linkage disequilibrium mapping, the construction of a physical contig of the regions of interest, and the screening of candidate genes for disease related mutations.

\section{LINKAGE ANALYSIS}

Conventional linkage analysis requires the study of extended, affected pedigrees in which the disease status of each individual and the mode of inheritance are known, with the assumption of a single disease locus. Such pedigrees are rarely, if ever, available for complex traits and mode of inheritance-the relative contributions of dominant, recessive, $\mathrm{X}$ linked, and/or mutifactorial inheritance, leading to the disease in the population of interest is often unknown. These assumptions do not apply to 'model free' non-parametric linkage analysis. Two statistical methods have been developed-affected sib pair and affected pedigree member analysis. ${ }^{74}$ The former method will be described here since it has been the most successful; affected pedigree member methodology is the least statistically powerful and still requires the construction of (albeit small) pedigrees.

Affected sib pair analysis ${ }^{75-77}$ conventionally involves the study of two affected relatives (siblings) in a pedigree to determine whether they have inherited identical copies of a chromosomal region from a common ancestor. This to some extent will happen by chance, but if seen in a large number of affected sibships the association between the chromosomal location and the disease becomes more significant. It has recently been suggested that the most efficient sib pair studies are those where sibs are either concordant (both exhibiting near identical features of the disease) or extremely disconcordant (one affected, the other normal). ${ }^{78}$ Since the identification of such disconcordant pairs, especially in ARMD and POAG, can be prone to diagnostic error (for example, a normal examination may not guarantee an unaffected status), concordant sib pairs are usually the better study design.

An important determination before undertaking such a study is to decide on the size of the sib pair group to be investigated. This is dependent firstly upon the total contribution that susceptibility loci make to the risk of developing the disease. This is called the risk ratio, $\mathrm{s}$, which may be calculated as the risk to a sibling of an affected proband versus the prevalence in the general population. For ARMD this is $10-30^{10} 79$ and for IDDM is $15^{40}$ The second important factor is the threshold to be accepted as a sign of significant linkage. This is determined by the maximum lod score statistic, $T$. For a monogenic disease $T=3$ corresponds to odds of $1: 1000$ in favour of linkage. During an initial total genome search (using marker loci 15 cM apart) susceptibility loci with $<2$ might be missed if the threshold used as suggestive of linkage were as high as this. Therefore at this stage $\mathrm{T}=1.5$ may be more appropriate. This was the situation with diabetes where many of the lesser susceptibility loci would have been missed if a high threshold had been used initially. ${ }^{80}$ In the case of ARMD however it has been suggested that a single genomic locus is associated with most of the genetic risk. ${ }^{16} \mathrm{~A}$ high threshold would still detect this locus. Many authors have proposed, and recent comparisons of concordance rates in monozygotic twins $-100 \%$ versus dizygotic twins- $28 \%$ to $42 \%{ }^{9}$ suggest, that underlying susceptibility to ARMD may involve a number of genes. ${ }^{81}$ The best interpretation of these studies therefore would be that a number of susceptibility loci are involved but that one locus is associated with most risk. Therefore, during a first stage genome search in ARMD, a maximum lod score statistic of $T=1.5$ would be prudent to ensure that these minor susceptibility loci are not missed. Using this information, power graphs based on Risch et al, ${ }^{76} 100$ sib pairs and polymorphic microsatellite markers at $\sim 15 \mathrm{cM}$ intervals, the probability of detecting minor susceptibility loci with 1.5 would be $>90 \%$.

The power statistic described above is based on haplotype data identical by descent (IBD). The power of affected sib pair studies in ARMD and POAG would be reduced to some extent since parental haplotypes would rarely be available and statistical analysis would be based on identical by state (IBS) data. In practice, this loss of power may be small especially if highly polymorphic microsatellite markers with polymorphism information contents (PIC) 0.8 were used. ${ }^{82}$

Loci highlighted during a first stage genome scan are then studied intensively using microsatellite markers mapping more densely in the regions of interest. When each locus is looked at closely true susceptibility loci will then give higher lod scores. In an affected sib pair analysis, significant linkage is obtained when $T=3.6$ and highly significant linkage when $\mathrm{T}=5.4{ }^{83} \mathrm{It}$ has also been suggested that to confirm the significance of identified susceptibility loci a second complete genome scan or a 'replication study' ${ }^{84}$ on an independent group of sib pairs be undertaken.$^{84}$ Failure to replicate a linkage result, however, may be due to population heterogeneity rather than suggesting error in the original study.

Simple affected sib pair analysis assumes that each locus identified contributes independently to disease susceptibility (genetic heterogeneity). As has been seen in diabetes, this may not be the case. Epistatic interaction occurs when the genotype at one locus has an effect on the contribution made by another locus. Such interactions suggest that the susceptibility genes at the two loci encode proteins that act 
on the same or related biochemical pathways. Epistasis is seen with the diabetes susceptibility loci IDDM1 and $I D D M 2^{85}$ and IDDM1, IDDM2, and IDDM7. ${ }^{86}$ Conversely, a genetic heterogeneity model best fits the interaction between IDDM1 and IDDM4 ${ }^{87}$ By undertaking such multilocus analysis ${ }^{88}$ not only is the true significance of a susceptibility locus better quantified but also clues as to the biochemical function of the localised disease gene may be obtained.

\section{LOCUS REFINEMENT}

Linkage refinement to a region smaller than $1-2 \mathrm{cM}$ is rarely achievable even when large, affected families are available. This is because recombination events rarely occur at this level. Such a refinement corresponds to approximately 1-2 megabases of DNA to search for mutations, a daunting task for the molecular geneticist. Linkage disequilibrium mapping is a technique that has been used successfully to help in such a situation. ${ }^{89}$ At the time a genetic mutation occurs the mutant allele will be completely linked-in linkage disequilibrium, with alleles of flanking markers. With time this association will decay. If it is assumed that this decay is due to recombination events only, a population based study of affected individuals and controls can be undertaken to compare the different frequencies of marker alleles in the two groups. The pattern or curve of disequilibrium between the disease and linked marker loci will exhibit a single maximum at the disease locus. The amount of linkage disequilibrium between a mutant allele and closely linked marker alleles can then be used to quantify the location of the disease relative to these marker alleles. In practice, however, other population genetic influences such as mutation, drift, breeding system, and selection influence this decay. The technique can therefore be imprecise depending on the statistical methodology employed. ${ }^{91}$ In part because of such influences, linkage disequilibrium mapping works best in genetically isolated populations. ${ }^{92}$

Linkage disequilibrium can also be used to investigate weak linkage reports. A good example is the IDDM2 localisation for which there is little evidence for linkage but strong evidence of linkage disequilibrium. This is because the locus has a true small effect but relatively few alleles in the population. ${ }^{93}$

\section{PHYSICAL MAPPING AND SCREENING CANDIDATE GENES}

Once sufficiently small genomic regions (for example, 1 megabase) have been identified using linkage analysis, with or without disequilibrium mapping, conventional studies have proceeded to the construction of physical contigs of each region of interest. Libraries of cloned genomic DNA fragments of various sizes are available. These fragments are amplified within various vectors-for example, yeast YACs (yeast artificial chromosomes) or bacteria cosmids, PACs (P1 artificial chromosomes), and BACs (bacterial artificial chromosomes). Such YACs or cosmids mapping to the region of interest are isolated from libraries by probing with microsatellite markers linked to the disease locus. An overlapping, ordered arrangement of clones is then constructed by sequencing the terminal ends of each fragment and then using this sequence to 'pull out' the next clone from the library. ${ }^{94}$ Once the contig is complete, various methods such as ' $\mathrm{CpG}$ island' mapping" and cDNA selection ${ }^{96}$ have been used to identify coding sequence which can then be screened-for example, using direct sequencing to identify polymorphisms or mutations associated with disease status.

Such physical mapping strategies are laborious, costly, and often inefficient. With the growing wealth of information on mapping and gene structure now available, a more fruitful strategy has often been to identify genes already known to map to the region of interest and screen the most likely candidates based on the known biochemistry of the condition of interest. Such a strategy is illustrated by the success of identifying TIMP3 as the disease gene in Sorsby fundus dystrophy within a large genomic region. ${ }^{20}$ Missense and nonsense mutations may be identified using (i) direct sequencing; (ii) the altered banding patters of single stranded DNA in non-denaturing gels (SSCP) ${ }^{97}$; (iii) resolution of heteroduplex molecules by virtue of their instability in denaturing gradient gels (DGGE) ${ }^{98}$; (iv) altered heteroduplex mobility in non-denaturing gels ${ }^{99}$; (v) chemical $^{100}$ or RNaseA cleavage methods ${ }^{101}$; (vi) by enzymic mismatch cleavage (EMC) using bacteriophage resolvase which recognises mismatch (mutant) bases and cuts the DNA at that site ${ }^{102}$; or (vii) oligonucleotide ligation assay (OLA) ${ }^{103}$ a fully automatable genotyping technique using oligonucleotides that end at a variable site to distinguish alleles. The latter two methods are particularly suited to the large scale identification of the intragenic polymorphisms most often associated with complex trait susceptibility. ${ }^{41}$

\section{Conclusions}

As is being shown in diabetes, in different groups of patients, different mutations and combinations of susceptibility loci may lead to disease. ${ }^{104}$ This makes the assessment of the true significance of environmental influences extremely difficult. One possible explanation for the conflicting reports on environmental influences in ARMD may be that particular external agents are only important to a subgroup of ARMD patients who have inherited one particular combination of disease susceptibility genes. With such an unsteady base to work from, progress towards a better understanding of ARMD, diabetic retinopathy, and glaucoma is best directed initially to determining the underlying genetic influences that predispose to these diseases. This is achievable with current molecular genetic technology and refined statistical methodology. Such information in itself would have practical benefits. Many therapeutic options are already available for diabetic retinopathy and glaucoma, which benefit from being applied early in the disease. Current clinical screening methods could be optimised by directing resources to those patients with proved genetic predispositions. In addition clinical treatment trials could be undertaken on genetically homogeneous groups of sufferers resulting in more meaningful and definitive conclusions.

Detailed genetic information on ARMD, diabetic retinopathy, and glaucoma will emerge over the next few years. It is to be expected that this will lead to dramatic changes in the way these important ophthalmic diseases are perceived, undoubtedly resulting in improved clinical management.

The authors thank Mr P Khaw, Mr I E Murdoch, and Professor S S Bhattacharya for their helpful suggestions during the preparation of this manuscript.

K EVANS A C BIRD

Department of Molecular Genetics, Institute of Ophthalmology

and Department of Clinical Ophthalmology,

Moorfields Eye Hospital,

London

1 Paterson AH. Molecular dissection of quantitative traits: progress and prospects. Genome Res 1995;5:321-33.

2 Cullinan TM. The epidemiology of blindness. In: Miller S, ed. Clinical oph thalmology. Bristol: Wright, 1987:571-8.

3 Evans J, Wormald $R$. Is the incidence of registrable age-related macular degeneration increasing? $\mathrm{Br} \mathcal{F}$ Ophthalmol 1996;80:9-14. 
4 The International ARM Epidemiological Study Group. An international classification and grading system for age-related maculopathy and

5 Jiménez-Sierra JM, Ogden TE, van Boemel GB. Inherited retinal diseases. A diagnostic guide. St Louis: C V Mosby, 1989

6 Hyman LG, Lilienfield AM, Ferris FL III, Fine SL. Senile macular degeneration; a case control study. Am f Epidemiol 1983; 118:213-27.

7 Dosso AA, Bovet J. Monozygotic twin brothers with age-related macular degeneration. Ophthalmologica 1992;205:24-8.

8 Meyers SM. A twin study on age-related macular degeneration. Trans Am Ophthalmol Soc 1994;92:775-843.

9 Klein MI, Maudlin WM, Stoumbos VD. Heredity and age-related macular degeneration. Observations in monozygotic twins. Arch Ophthalmol 1995;112:932-7.

10 Silvestri G, Johnson PB, Hughes AE. Is genetic predisposition an important risk factor in age-related macular degeneration? Eye 1994;8:564-8.

11 Piguet B, Wells JA, Palmvang IB, Wormald R, Chisholm IH, Bird AC. Agerelated Bruch's membrane change: a clinical study of the relative role of heredity and environment. Br f Ophthalmol 1993;77:400-3

12 Leibowitz H, Krueger D, Maunder L, Milton RC, Kini MM, Kahn HA, et al. The Framingham Eye Study monograph. Surv Ophthalmol 1980; 24(suppl):428-35.

13 Klein R, Rowland ML, Harris MI. Racial/ethnic differences in age-related maculopathy: Third National Health and nutritional examination survey. maculopathy: Third National Heal

14 Pieramici DJ, Bressler NM, Schachat AP. Choroidal neovascularisation in black patients. Arch Ophthalmol 1994;112:1043-6.

15 Holz FG, Piguet B, Minassian DC, Bird AC, Weale RA. Decreasing stromal iris pigmentation as a risk factor for age-related macular degeneration. $A m$ f Ophthalmol 1994 117:19-23.

16 Heiba IM, Elston RC, Klein BEK, Klein R. Sibling correlations and segregation analysis of age-related maculopathy: the Beaver Dam Eye Study. Gen Epidemiol 1994;11:51-67.

17 Bird AC. Retinal photoreceptor dystrophies. Ll. Edward Jackson Memorial Lecture. Am f Ophthalmol 1995;118:543-62.

18 Héon E, Piguet B, Munier F, Sneed SR, Morgan CM, Forni S, et al. Linkage of autosomal dominant radial drusen (malattia levantinese) to chromosome 2p16-21. Nature Genet 1996;114:193-8.

19 Apfelstedt-Sylla E, Theischen M, Ruther K, Wedemann H, Gal A, Zrenner E. Extensive intrafamilial and interfamilial phenotypic variation amon patients with autosomal dominant retinal dystrophy and muations in the human RDS/peripherin gene. Br F Ophthalmol 1995;79:28-34.

20 Weber, BHF, Vogt G, Pruett RC, Stohr H, Felbor U. Mutations in the tissue inhibitor of metalloproteinases-3 (TIMP3) in patients with Sorsby's fundus dystrophy. Nature Genet 1994;8:352-6.

21 Khan H, Leibowitz H, Ganley J, Kini MM, Colton T, Nickerson RS, et al. The Framingham Eye Study II. Association of ophthalmic pathology with single variables previously measured in the Framlingham Heart Study. $A m$ $千$ Epidemiol 1977;106:33-41.

22 Vingerling JR, Dielemans I, Bots ML, Hofman A, Grobbee DE, DeJong PTVM. Age-related macular degeneration is accociated with atherosclerosis - the Rotterdam study. Am f Epidemiol 1995;142:404-9.

23 Ritter LL, Klein R, Klein BE Mares-Pelman JA, Jensen SC. Alcohol use and age-related maculopathy in the Beaver Dam Eye Study. Am $\mathcal{f}$ Ophthalmo 1995;120:190-6.

24 Vingerling JR, Dielemans I, Witteman JCM, Hofman A, Grobbee DE, De Jong PTVM. Macular degeneration and early menopause: a case-contro study. $B M \mathcal{F}$ 1995;310:1570-1.

25 Klein R, Klein BEK, Linton KLP, Demets DL. The Beaver Dam Eye Study: the relation of age-related maculopathy to smoking. Am $\mathcal{Y}$ Epidemiol 1993 137:190-200.

26 Bird AC. Doyne lecture: Pathogenesis of retinal pigment epithelial detachment in the elderly; the relevance of Bruch's membrane change. Ey 1991;5:1-12.

27 Chew EY. Nutritional suppliment use and age-related macular degeneration. Curr Opin Ophthalmol 1995;6:19-24.

28 West S, Vitale S, Hallfrisch J, Munoz B, Muller D, Bressler S, et al. Are antioxidants or supplements protective for age-related macular degeneration. Arch Ophthalmol 1994;112:222-7.

29 Mares-Pelman JA, Brady WE, Klein R, Klein BEK, Bowen P, StecewiczApuntzakis $M$, et al. Serum antioxidants and age-related macula degeneration in a population based case-control study. Arch Ophthalmol 1995;113:1518-23.

30 Klein R, Klein BEK, Moss SE, Davis MD, DeMets DL. Glycosylated hemoglobin predicts the incidence and progression of diabetic retinopathy. fAMA 1988;268:2864-71.

31 Diabetes Control and Complications Trial Research Group. The effect of intensive diabetes treatment on the progression of diabetic retinopathy in insulin-dependent diabetes. Arch Ophthalmol 1995;113:36-51.

32 Caird FI, Pirie A, Ramsell TG. Diabetes and the eye. Oxford: Blackwell Scientific Press, 1969:140-62.

33 Vialettes B, Paquisfluchinger V, Silvestreailland P, Bendaham D, Pelissier JF, Etcharybouyx $\mathrm{F}$, et al. Extra-pancreatic manifestations in diabetes secondary to mitochondrial-DNA point mutations within the tRNA (Leu)UUR ary to mitochondrial-DNA point mutt

34 Gerbitz KD, Gempel K, Bradiczka D. Mitochondria and diabetes-genetic, biochemical and clinical implications of the cellular energy circuit. Diabetes 1996;45:113-26.

35 Klein R, Klein BEK, Moss SE, Davis MD, DeMets DL. The Wisconsin epidemiologic study of diabetic retinopathy II. Prevalence and risk of diabetic retinopathy when age at diagnosis is less that 30 years. Arch Ophthalmol 1984;102:520-6.

36 Klein R, Klein BEK, Moss SE, Davis MD, DeMets DL. The Wisconsin epidemiologic study of diabetic retinopathy III. Prevalence and risk of diabetic retinopathy when age at diagnosis is 30 or more years. Arch Ophthalmol 1984;102:527-32.

37 Rand LI, Krolewski AS, Aiello LM, Warram JH, Baker RS, Maki T. Multiple factors in the prediction of risk of proliferative diabetic retinopathy. $N$ Engl fMed 1985;313:1433-8.

38 Chowdhury TA, Kumar S, Barnett AH, Bain SC. Nephropathy in type diabetes: the role of genetic factors. Diabetic Med 1995;12:1059-67.

39 Todd JA. The emperor's new genes: 1993 RD Lawrence lecture. Diabetic Med 1994;11:6-16.
40 Cordell HJ, Todd JA. Multifactorial inheritance in type 1 diabetes. TIGS 1995;11:499-504.

41 Kennedy GC, German MS, Rutter WJ. The minisatellite in the diabetes susceptibility locus IDDM2 regulates insulin transcription. Nature Genet 1995;9:293-8.

42 Newman B, Selby J, King M-C, Slemenda C, Fabsitz R, Friedman G. Concordance for type 2 (non-insulin-dependent) diabetes mellitus in male twins). Diabetologia 1987;30:763-8.

43 Kaprio J, Tuomilehto J, Koshenvuo M, Romanov K, Reuanen A, Eriksson J, et al. Concordance for type 1 (insulin-dependent) and type 2 (non-insulindependent) diabetes mellitus in a population-based cohort of twins in Finland. Diabetologia 1992;35:1060-7.

44 Rich SS. Mapping genes in diabetes. Genetic epidemiological perspective. Diabetes 1990;39:1315-9.

45 Ghosh S. Probability and complex disease genes. Nature Genet 1995;9: 223-4.

46 Hager J, Hansen L, Vaiisse C, Vionnet N, Pilippi A, Poller W, et al. A missense mutation in the glucagon receptor gene is associated with non-insulin dependent diabetes mellitus. Nature Genet 1995;9:299-304.

47 Galli J, Luo-Sheng L, Glaser A, Claes-Göran O, Jiao H, Fakhari-Rad H, et al. Genetic analysis of non-insulin dependent diabetes mellitus in the GK rat. Nature Genet 1996;12:31-7.

48 Gauguier D, Froguel P, Parent V, Bernard C, Bihoreau M-T, Portha B, et al. Chromosomal mapping of genetic loci associated with non-insulin dependent diabetes in the GK rat. Nature Genet 1996;12:38-43.

49 Permutt MA, Ghosh S. Rat model contributes new loci for NIDDM susceptibility in man. Nature Genet 1996;12:4-6.

50 Nystrom L Dahlquist G, Rewers M, Wall S. The Swedish childhood diabetes study. An analysis of the temporal variation in diabetes incidence 19781987. Int $₹$ Epidemiol 1990;1:141-6.

51 Bodington MJ, Muzulu SI, Burden AC. Spatial clustering in childhood diabetes: evidence of an environmental cause. Diabetic Med 1995;12:865-7.

52 Olmos P, A'Hern R, Heaton DA, Millward BA, Risley D, Pyke DA, et al. Significance of the concordance rate in type 1 (insulin-dependent) diabetes in identical twins. Diabetologia 1988;31:747-50.

53 Pak CY, Hyone-Myong E, McArthur RG, Yoon JW. Association of cytomegalovirus infection with autoimmune type 1 diabetes. Lancet 1988;ii:1-4.

44 Todd JA A protective role of the environment in the development of type 1 diabetes ? Diabetic Med 1991;8:906-10.

55 Frank RN. Etiologic mechanisms in diabetic retinopathy. In: Ryan SJ, ed. Retina. II Medical retina. St Louis: CV Mosby, 1994

56 Gencik A. Epidemiology and genetics of primary congenital glaucoma in Slovakia. Description of a form of primary congenital glaucoma in gypsies with autosomal recessive inheritance and complete penetrance. Dev Ophthalmol 1989;16:76-115.

57 Pastor SA, Williams RD, Hoskins HD. Congenital and juvenile glaucoma. Curr Opin Ophthalmol 1992;3:154-8.

58 Lee DA, Brubaker RF, Hruska L. Hereditary glaucomas: a report of two pedigrees. Ann Ophthalmol 1985;17:739-41.

59 Johnson AT, Drack AV, Kwite AE, Cannon RL, Stone EM, Alward WLM. Clinical features and linkage analysis of a family with autosomal dominant juvenile glaucoma. Ophthalmology 1993;100:524-9.

60 Kitsos G, Cote G, Psilas K. Un exemple d'hérédité dominante pour la transmission du glaucome primitif à angle ouvert dans une région du nordouest de la Grèce. $\mathcal{F}$ Fr Ophtalmol 1988;11:859-64.

61 François J. Genetics and primary open-angle glaucoma. Am f Ophthalmol 1966,61:652-65.

62 Leighton DA. Survey of first degree relatives of glaucoma patients. Trans Ophthalmol Soc UK 1976,96:28-32.

63 Drance SM, Schulzer M, Thomas B, Douglas GR. Multivariate analysis in glaucoma. Use of discriminant analysis in predicting glaucomatous visual glaucoma. Use of discriminant analysis in pred

64 Perkins ES. Family studies in glaucoma. Br f Ophthalmol 1974;58:529-35.

65 Teikari T. Genetic factors in open-angle (simple and capsular) glaucoma. A population-based twin study. Acta Ophthalmol (C) 1987;65:715-20.

66 Stewart WC. The effect of lifestyle on the relative risk to develop open-angle glaucoma. Curr Opin Ophthalmol 1995;6:3-9.

67 Sarfarazi M, Akarsu AN, Hossain A, Turacli E, Aktan SG, Barsoum-Homsy $\mathrm{MB}$, et al. Assignment of a locus (GLC3A) for primary congenital glaucoma (buphthalmos) to $2 \mathrm{p} 21$ and evidence for genetic heterogeneity. Genomics 1995;30:171-7.

68 Richards JE, Lichter PR, Boehnke M, Uro JLA, Torrez D, Wong D, et al. Mapping of a gene for autosomal dominant juvenile-onset open-angle glaucoma to chromosome 1q. Am 7 Hum Genet 1994;54:62-70.

69 Wiggs JL, Hains JL, Paglinauan C, Fine A, Sporn C, Lou D. Genetic linkage analysis of autosomal dominant juvenile glaucoma to $1 \mathrm{q} 21-\mathrm{q} 31$ in three analysis of autosomal dominant juvenile glaucon

70 Morissette J, Côte G, Anctil J-L, Plante M, Amyot M, Héon E, et al. A common gene for juvenile and adult onset primary open-angle glaucomas confined on chromosome 1q. Am $\mathcal{F}$ Hum Genet 1995;56:1431-42.

71 Foot S. Genetic-analysis of disease susceptibility (disease susceptibility) Aust NZ F Med 1995;25:757-60.

72 Davis A, Cowell JK. Mutations in the PAX6 gene in patients with hereditary aniridia. Hum Mol Genet 1993;2:2093-7.

73 Gorin MB, Wright AF. Background to molecular genetic principles and techniques. In: Wright AF, Jay B, eds. Molecular genetics of inherited eye disorders. Switzerland: Harwood Academic Press, 1994:1-28.

74 Weeks DE, Lathrop GM. Polygenic disease: methods for mapping complex disease traits. TIGS 1995;11:513-9.

75 Risch N. Linkage strategies for genetically complex traits I. Multilocus models. Am f Hum Genet 1990a;46:222-8.

76 Risch N. Linkage strategies for genetically complex traits II. The power of affected relative pairs. Am $\mathcal{F}$ Hum Genet 1990b;46:229-41.

77 Risch N. Linkage strategies for genetically complex traits III. The effect of marker polymorphism on analysis of affected relative pairs. Am $\mathcal{F}$ Hum Genet 1990c;46:242-53.

78 Risch N, Zhang H. Extreme discordant sib pairs for mapping quantitative trait loci in humans. Science 1995;268:1584-9.

79 Mitchell P, Smith W, Attebo K, Wang JJ. Prevalence of age-related maculopathy in Australia. The Blue Mountains Eye Study. Ophthalmology 1995;102:1450-60.

80 Davies JL, Kawaguchi Y, Bennett ST, Copeman JB, Cordell HJ, Pritchard $\mathrm{LE}$, et al. A genome-wide search for human type 1 diabetes susceptibility genes. Nature 1994;371:130-6. 
81 Pickles A, Bolton P, MacDonald H Bailey A, Lecouteur A, Sim CH, et al. Latent-class analysis of recurrence risks for complex phenotypes with selection and measurement error-a twin and family history study of autism. Am ₹ Hum Genet 1995;57:717-26.

82 Holmans P. Asymptotic properties of affected-sib-pair linkage analysis. $\mathrm{Am}$ 7 Hum Genet 1993;52:362-74.

83 Lander E, Kruglyak L. Genetic dissection of complex traits: guidelines for interpreting and reporting linkage results. Nature Genet 1995;11:241-7.

84 Sham P. Sequential-analysis and case-control candidate gene association Sham P. Sequential-analysis and case-control
studies-reply. Am $₹$ Med Genet 1994;54:154-5

85 Dizier MH, Babron M-C, Clerget-Darpoux F. Interactive effect of two candidate genes in a disease: extension of the marker-association-segregation 2 method. Am ₹ Hum Genet 1994;55:1042-9.

86 Owerbach D, Gabbay KH. The HOXDS locus (2q31) is linked to type 1 diabetes-interaction with chromosome 6 and chromosome 11 disease susceptibility genes. Diabetes $1995 ; 44: 132-6$.

87 Cordell HJ, Todd JA, Bennett ST, Kawaguchi Y, Farrall M. Two-locus maximum lod score analysis of a multifactorial trait: joint consideration of IDDM2 and IDDM4 with IDDM1 in type 1 diabetes. Am $₹$ Hum Genet 1995;57:920-34.

88 Schock NJ, Boehnke M, Terwilliger JD, Ott J. Two-trait-locus linkage analysis: a powerful strategy for mapping complex genetic traits. Am $\mathfrak{f} \mathrm{Hum}$ Genet 1993;53:1127-36.

89 Rommens HM, Iannuzzi MC, Kerem B, Drumm ML, Melmer G, Dean N et al. Identification of the cystic fibrosis gene: chromosome walking and jumping. Science 1989;245:1059-65.

90 Kerem B, Rommens JM, Buchanan JA, Markiewicz D, Cox TK Chakravarti A, et al. Identification of the cystic fibrosis gene: genetic analysis. Science 1989;245:1073-80.

91 Devlin B, Risch N. A comparison of linkage disequilibrium measures for fine scale mapping. Genomics 1995;29:311-22.

92 Hästbacka J, de la Chapelle A, Mahanti MM, Clines G, Reeves-Daly MP Daly $M$, et al. The diastrophic dysplasia gene encodes a novel sulphate transporter; positional cloning by fine-structure linkage disequilibrium mapping. Cell 1994;78:1073-87.
93 Spielman RS, McGinnis RE, Ewens WJ. Transmission test for linkage isequilibrium: the insulin gene region and insulin-dependent diabetes mellitus (IDDM). Am ₹ Hum Genet 1993;52:506-16.

94 Keen TJ, Inglehearn CF, Green ED, Cunningham AF, Patel RJ, Peacock $\mathrm{RE}$, et al. A YAC contig spanning the dominant retinitis pigmentosa locus (RP9) on chromosome 7p. Genomics 1995;28:383-8.

95 Cotton RGH. Current methods of mutation detection. Mutation Res 1993 285:125-44.

96 Parimoo S, Kolluri R, Weissman SM. cDNA selection from total yeast DNA containing YACs. Nucleic Acid Res 1993;21:4422-3.

97 Orita M, Suzuki Y, Sekity AT, Hyashi K. Rapid and sensitive detection of point mutations and DNA polymorphisms using the polymerase chain reaction. Genomics 1989;5:874-9.

98 Nichols BE, Sheffield VC, Vandenburgh K, Drack AV, Kimura AE, Stone EM. Butterfly-shaped pioment dystrophy of the fovea caused by a point mutation in codon 167 of the RDS gene. Nature Genet 1993;3:202-6.

99 Keen TJ, Inglehearn CF, Kim R, Bird AC, Bhattacharya S. Retinal pattern dystrophy associated with a 4 bp insertion at codon 140 in the RDS-peripherin gene. Hum Mol Genet 1994;3:367-8.

100 Cotton RGH, Rodrigues NR, Campbell DR. Reactivity of cytosine and thymine in single-base-pair mismatches with hydroxamine and osmium tetroxide and its application to the study of mutations. Proc Natl Acad Sci USA 1988;85:4397-401.

101 Myers RM, Larin Z, Maniatis T. Detection of single base substitutions by ribonuclease cleavage at mismatches in RNA-DNA duplexes. Science 1985; 230:1242-6.

102 Mashal RD, Koontz J, Sklar J. Detection of mutations by cleavage of DNA heteroduplexes with bacteriophage resolvases. Nature Genet 1995;9:17783.

103 Nickerson DA, Kaisser R, Lappin S, Stewart J, Hood L, Landegren U. Automated DNA diagnostics using an ELISA-based oligonucleotide Automated DNA diagnostics using an ELISA-based

104 Todd JA, Aitman TJ, Cornall RJ, Ghosh S, Hall RJS, Hearne CM, et al. Genetic analysis of autoimmune type 1 diabetes mellitus in mice. Nature 1991;351:542-7. 